\title{
Aquifer Thermal Energy Storage: A Well Doublet Experiment at Increased Temperatures
}

\author{
F. J. Molz, J. G. Melville, A. D. ParR, ${ }^{1}$ D. A. King, and M. T. Hopf \\ Civil Engineering Department, Auburn University, Auburn, Alabama 36849
}

\begin{abstract}
The two main objectives of this communication are to present a study of potential advantages and disadvantages of the doublet supply-injection well configuration in an aquifer thermal energy storage (ATES) system and to report on aquifer storage problerns with injection temperatures in the $80^{\circ} \mathrm{C}$ range. $\mathrm{A}$ 3-month injection-storage-recovery cycle followed by a 7.3-month cycle constituted the main experiment. The injection volumes were $25,402 \mathrm{~m}^{3}$ and $58,063 \mathrm{~m}^{3}$ at average temperatures of $58.5^{\circ} \mathrm{C}$ and $81^{\circ} \mathrm{C}$ respectively. Unlikely previous experiments at the Mobile site, no clogging of the injection well due to clay particle swelling, dispersion, and migration was observed. This is attributed to the fact that the supply water used for injection contained a cation concentration equal to or slightly greater than that in the native groundwater. For cycles I and II, the fraction of injected energy recovered in a volume of water equal to the injection volume was 0.56 and 0.45 respectively. Both groundwater temperature and tracer data support the conclusion that this relatively low recovery was due to the detrimental effects of free thermal convection, possibly augmented by longitudinal zones of high permeability. Construction of a partially penetrating recovery well improved recovery efficiency but is not thought to be an adequate solution to thermal stratification. A maximum increase of $1.24 \mathrm{~cm}$ in relative land surface elevation was recorded near the end of second cycle injection. The engineering implications of such an elevation change would have to be considered, especially if an ATES system were being designed in an urban environment. A third cycle was started at the Mobile site on April 7, 1982. This final experiment contains a partially penetrating, dual-recovery well system which is expected to maximize energy recovery from a thermally stratified storage aquifer.
\end{abstract}

\section{INTRODUCTION}

Aquifer thermal energy storage (ATES) is continuing to receive international attention as a possible means for storing large amounts of energy at low cost and with little heat loss. There are experiments recently completed or presently under way in Canada, Denmark, France, Germany, Japan, Sweden, Switzerland, and the United States. Many of these projects are concerned with practical application of the ATES concept, for either heating or cooling. Current information on the international effort may be obtained from the proceedings of the October 1981 symposium on seasonal thermal energy storage organized by the Battelle Pacific Northwest Laboratories [U.S. Department of Energy, 1981] and from the various quarterly issues of the Seasonal Thermal Energy Storage Newsletter published by the Lawrence Berkeley Laboratory in 1981 and 1982.

Beginning in 1975, Auburn University conducted two sets of ATES experiments in a confined aquifer near Mobile, Alabama. At that location, the ambient groundwater temperature is $20^{\circ} \mathrm{C}$. The first experiment was composed of an 85-day injectionstorage-recovery cycle involving $7570 \mathrm{~m}^{3}$ of $37^{\circ} \mathrm{C}$ filtered water from an electric power plant thermal discharge canal [Molz et al., 1978]. Near the end of recovery pumping, $53 \%$ of the injected thermal energy was recovered in a volume equal to the injection volume. There was some uncertainty about this percentage because of assumed leakage from the storage aquifer during injection [Papadopulos and Larson, 1978]. In view of the small storage volume, however, the fraction of energy recovered was considered promising.

\footnotetext{
${ }^{1}$ Now at Department of Civil Engineering, University of Kansas, Lawrence, Kansas 66044.

Copyright 1983 by the American Geophysical Union.

A second set of experiments were designed in 1977. They utilized the same well field that was constructed for the preliminary experiment, but consisted of two injection-storagerecovery cycles, each approximately of 6 months duration. In each cycle, water was pumped from a relatively shallow supply aquifer, heated to an average temperature of $55^{\circ} \mathrm{C}$ with an oil-fired water heater, and injected into the deeper storage aquifer [Molz et al., 1979, 1981]. Injection volumes were 55,000 $\mathrm{m}^{3}$ and $58,000 \mathrm{~m}^{3}$ respectively. Energy recoveries of $66 \%$ and $76 \%$ respectively at temperatures above $33^{\circ} \mathrm{C}$ and in volumes of water approximately equal to the injection volumes are the best that have been obtained to date in an ATES experiment. A computer model developed by the Lawrence-Berkeley Laboratory was able to simulate the data quite well [Tsang et al., 1981]. A simplified model that can be used to evaluate and design ATES systems is available also [Doughty et al., 1982].

An important negative result of the previously referenced experiments at the Mobile site was clogging of the injectionproduction well during injection. The clogging problem during the first experiment was at least partly related to the suspended solids content of the canal supply water [Molz et al., 1978]. However, clogging persisted during later experiments [Molz et al., 1979, 1981]. After some study it was concluded that the chemical difference between water from the storage and supply aquifers was causing clay components in the storage aquifer to swell, disperse, and migrate. The phenomenon involved is called osmotic swelling [Brown and Silvey, 1977; van Olphen, 1963] and can occur when water having a relatively low ion content is pumped into an aquifer having a relatively high ion concentration. It is but one of several mechanisms which can cause chemical-induced clogging of storage aquifers [Parr et al., 1983].

Several individuals have suggested that using water from the storage aquifer as supply water for the boiler or other heating system will minimize clogging problems of a chemically induced nature. Drilling the supply well and the injection- 
production well in the same formation is often called the doublet well configuration. If aquifer storage of thermal energy becomes feasible on a commercial scale, it seems likely that a system based on the doublet configuration will offer distinct advantages. Hence there is a real need to study this concept experimentally so that potential advantages and disadvantages can be identified clearly before major amounts of money are invested. Reporting such a study is a major objective of the present paper.

There are obvious advantages to storing water at higher temperatures. However, potential problems arise also. Detrimental chemical reactions, if any, will accelerate with temperature. In addition, the density of water decreases with temperature, and buoyancy-induced flow (free thermal convection) could become important. Convection could have a marked negative effect on energy recovery because the relatively light hotter water would float to the top of the aquifer and spread laterally. Recovery pumping would then mix hot water from the top of the aquifer with cold water from the bottom. A second major objective of this paper is to report on aquifer storage problems at the Mobile site with injection temperatures in the $80^{\circ} \mathrm{C}$ to $90^{\circ} \mathrm{C}$ range.

\section{DESCRIPTION OF EXPERIMENTS}

The project site is located in a soil borrow area at the Barry Steam Plant of the Alabama Power Company, about $32 \mathrm{~km}$ north of Mobile, Alabama (see Molz et al. [1978] for details). The surface area consists of a low-terrace deposit of Quaternary age consisting of interbedded sands and clays that have, in geologic time, been recently deposited along the western edge of the Mobile River. These sand and clay deposits extend to a depth of approximately $61 \mathrm{~m}$ where the contact between the Tertiary and Quaternary geologic eras is located. Below the contact, deposits of the Miocene series are found that consist of undifferentiated sands, silty clays, and thin-bedded limestones extending to an approximate depth of $305 \mathrm{~m}$.

The well field was established in the Quaternary deposits, and on the basis of drilling logs the fence diagram shown in Figure 1 was constructed. Each vertical line on the diagram represents a well of some type. These wells were screened in the

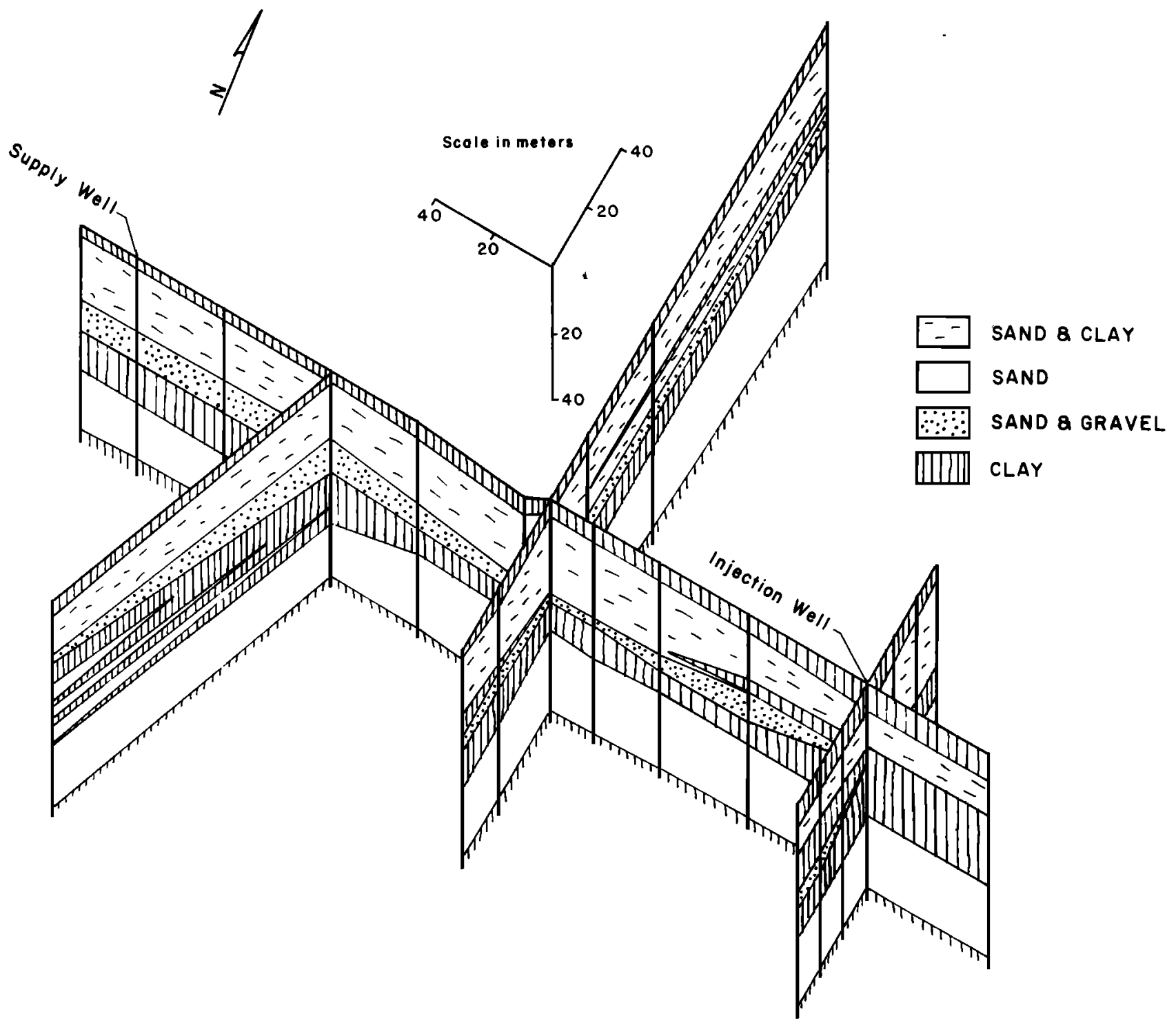

Fig. 1. Fence diagram of the subsurface hydrologic system at the Mobile site. The sand formation constitutes the storage aquifer. 
TABLE 1. Summary of Measured and Estimated Aquifer Characteristics

\begin{tabular}{ll}
\hline \multicolumn{1}{c}{ Parameter } & \multicolumn{1}{c}{ Value } \\
\hline $\begin{array}{l}\text { Thermal conductivity } \\
\text { Aquifer }\end{array}$ & $1.98 \times 10^{5} \mathrm{~J} \mathrm{~m}^{-1} \mathrm{~d}^{-1}{ }^{\circ} \mathrm{C}^{-1}\left(31.8 \mathrm{Btu} \mathrm{ft} \mathrm{ft}^{-1} \mathrm{~d}^{-1}{ }^{\circ} \mathrm{F}^{-1}\right)$ \\
Aquitards & $2.21 \times 10^{5} \mathrm{~J} \mathrm{~m}^{-1} \mathrm{~d}^{-1}{ }^{\circ} \mathrm{C}^{-1}\left(35.5 \mathrm{Btu} \mathrm{f}^{-1} \mathrm{~d}^{-1} \mathrm{o}^{-1}\right)$ \\
Heat capacity & $1.81 \times 10^{6} \mathrm{~J} \mathrm{~m}^{-3}{ }^{\circ} \mathrm{C}^{-1}\left(27.0 \mathrm{Btu} \mathrm{ft} \mathrm{ft}^{-3} \mathrm{~F}^{-1}\right)^{*}$ \\
Hydraulic conductivity (horizontal) & $44 \mathrm{~m} / \mathrm{d}(144 \mathrm{ft} / \mathrm{d})$ \\
1976 test & $53.6 \mathrm{~m} / \mathrm{d}(175.8 \mathrm{ft} / \mathrm{d})$ \\
1980 partially penetrating test & $53.4 \mathrm{~m} / \mathrm{d}(175.3 \mathrm{ft} / \mathrm{d})$ \\
1980 fully penetrating test & $7.66 \mathrm{~m} / \mathrm{d}(25.1 \mathrm{ft} / \mathrm{d})$ \\
Hydraulic conductivity (vertical) & $5 \times 10^{-4}$ \\
1980 partially penetrating test & $4.9 \times 10^{-4}$ \\
Aquifer storativity & $6.4 \times 10^{-4}$ \\
1976 test & 0.33 \\
1980 partially penetrating test & \\
1980 fully penetrating test & \\
Estimated aquifer porosity &
\end{tabular}

* An estimate for typical materials.

sand formation which extends from approximately 39 to $61 \mathrm{~m}$ below the land surface. This formation constitutes the confined aquifer used for thermal energy storage.

Because the data collected in the present experiments are serving as the basis for rather extensive mathematical modeling studies, more than the usual attempt was made to determine accurate hydraulic properties of the storage aquifer and aquitards. These properties included both vertical and horizontal permeability of the storage aquifer, storativity, and vertical diffusivity of the upper and lower aquitards. Thermodynamic properties such as thermal conductivity and heat capacity are important also and were measured or estimated in previous studies [Molz et al., 1978]. A detailed description of preinjection aquifer testing at the Mobile site may be found in the work by Parr et al. [1983]. A summary of relevant properties which were measured or estimated is given in Table 1 .

As was mentioned in the introduction, an important objective of the present experiments was to ascertain if using storage formation water as supply water for heating would eliminate the clogging problems which were observed in previous experiments. In order to eliminate any effects due to earlier experi- ments, a new storage zone was selected on the eastern side of the original well field (Figure 2). A new injection-recovery well (I2) was drilled and surrounded by observation wells designed to measure temperature, hydraulic head, or tracer concentration. (The old storage zone was located in the vicinity of the boiler shown in Figure 2.) Several existing observation wells were incorporated into the new well field.

Observation wells that were used to measure temperature in the storage formation were constructed as shown in Figure 3. Thermistors were employed to measure temperature at six locations in each well. Two thermistors were installed at each location to provide a backup array. The wells were backfilled with sand in order to minimize unrepresentative thermal convection within the well bores. Temperature was measured also in the upper and lower aquitards. One well is screened in each of the aquitards, and temperature was measured at two locations in each well. The observation wells that were used to measure hydraulic head were constructed similar to the temperature wells but, of course, were not backfilled with sand.

Tracer injection and sampling were performed to compare the movements of solute and heat in the aquifer. A chemical

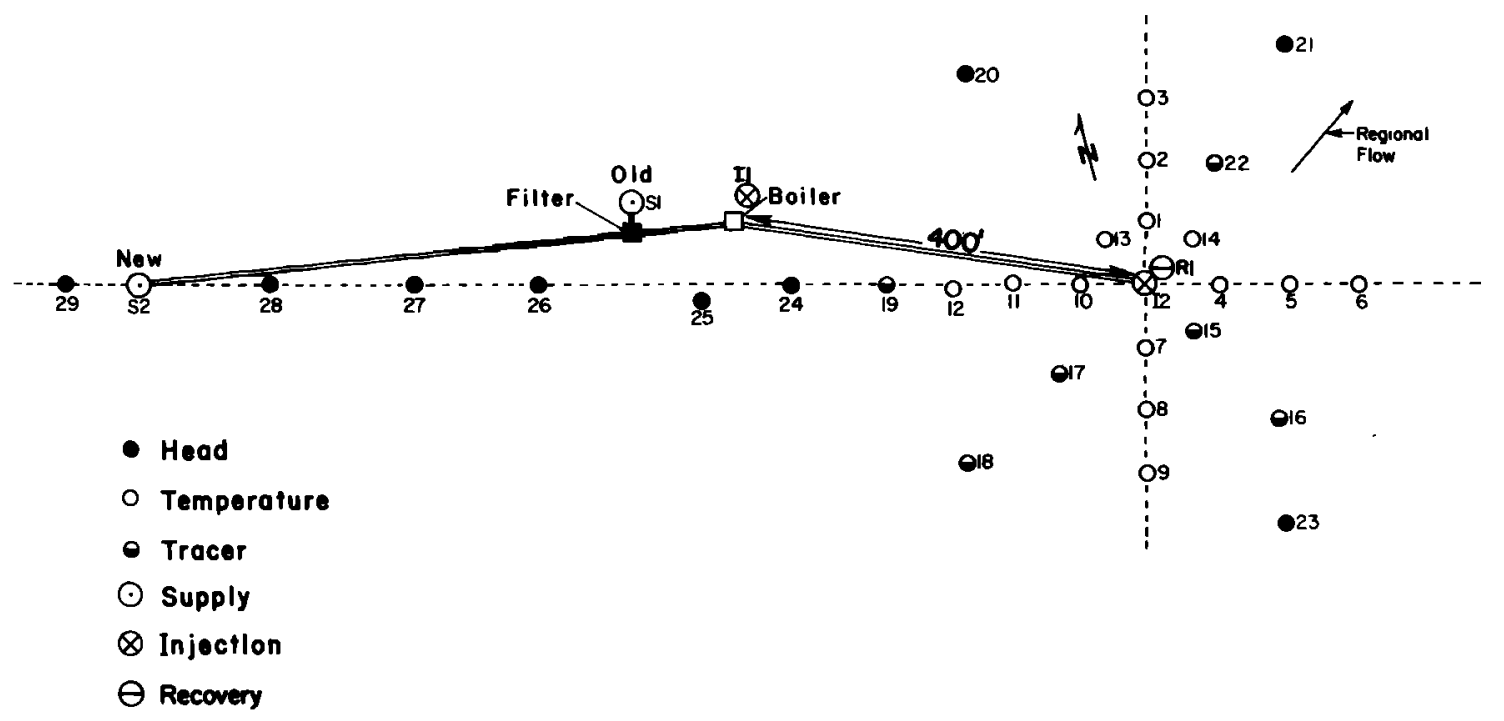

Fig. 2. Top view of the well field at the Mobile site showing the different types of wells. 


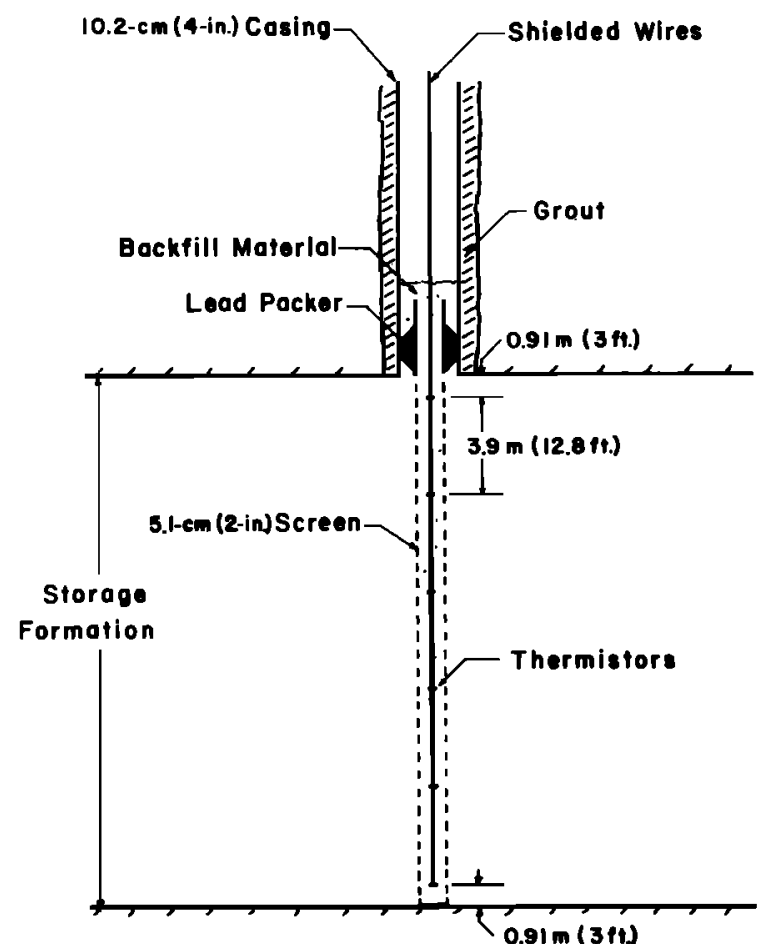

Fig. 3. Schematic diagram of a typical temperature observation well.

feed system was used to inject sodium bromide into the hot water pipeline throughout the first injection (Figure 4). Water samples were obtained from wells $12,15,16$, and 22 so that tracer concentration could be recorded as a function of time. Rather than continuous tracer injection, two slugs of tracer were added to the supply water during the first week of second cycle injection.

Hot water pumped from the injection well (I2) during the recovery phase of each cycle was returned to the confined aquifer through the supply well (S2) in order to minimize the amount of energy needed to heat water for subsequent injections. It was anticipated that this procedure may create clogging problems, however, since the concentration of clay particles in the pumped water may tend to increase with repeated cycles. In order to control clogging and to maintain acceptable injection rates, a rapid sand-filtering system was installed. The filtering system can either be used or bypassed during the injection and recovery phases.

At regular intervals during both cycles, careful level measurements were made so that additional data could be obtained on the magnitude of land surface elevation changes caused by ATES at the Mobile site [Molz et al., 1981]. The locations of the reference, observation, and measurement pads are shown in

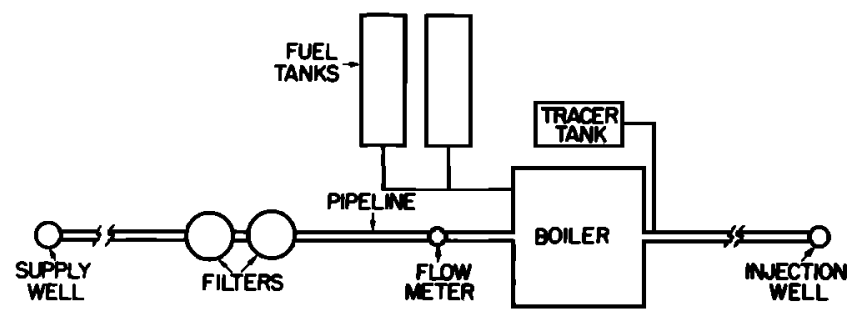

Fig. 4. Schematic diagram showing the tracer tank, boiler, and associated equipment at the Mobile site.
Figure 5. Each pad was constructed of reinforced concrete with a surveying marker embedded in the center. A level was placed on the observation pad, and from this location, relative elevations of the markers on pads $A$ and $B$ with respect to those on pads $C$ and $D$ were recorded.

A 3-month injection-storage-recovery cycle followed by a 7.3-month cycle constituted the main experiment. The average injection temperatures were $58.5^{\circ} \mathrm{C}$ and $81^{\circ} \mathrm{C}$ respectively. Shown in Figures 6 and 7 are the cumulative injection volumes for each cycle. Cycle I injection began on February 17, 1981, and continued on an intermittent basis until March 21, 1981, when $25,402 \mathrm{~m}^{3}$ of water had been injected. Injection temperature versus time is shown in Figure 8. Recovery pumping was initiated on April 21, 1981, and continued until May 17, 1981. First cycle recovery rate as a function of time is shown in Figure 9. The total volume recovered was $28,924 \mathrm{~m}^{3}$.

Second cycle injection of $58,063 \mathrm{~m}^{3}$ of heated water began on June 12,1981 , and continued intermittently until October 27 , 1981. The injection rate was slower than anticipated because the water heater was operating near its capacity, and in order to maintain a higher injection temperature without firebox overheating the flow rate was reduced to approximately $0.45 \mathrm{~m}^{3}$ $\min ^{-1}$. The resulting injection temperature versus time curve is shown in Figure 10. After 34 days of storage, production began on November 30,1981, and continued until January 23, 1982, at which time $60,575 \mathrm{~m}^{3}$ of water had been recovered at an average rate of $0.8 \mathrm{~m}^{3} \mathrm{~min}^{-1}$ as shown in Figure 11 .

\section{Results of First CyCle}

The temperature history at the recovery well is shown in Figure 12. While the average injection temperature near the end of injection was $52^{\circ} \mathrm{C}$ and prior to that was $58^{\circ} \mathrm{C}$ or higher, the initial recovery temperature was less than $48^{\circ} \mathrm{C}$. This difference in temperatures between the end of injection and the beginning of recovery was not observed during earlier, comparable experiments at the Mobile site [Molz et al., 1979, 1981] and suggested that a previously unobserved heat loss mechanism was operating. The fundamental differences between this experiment and earlier experiments were that the injection volume $\left(25,402 \mathrm{~m}^{3}\right)$ was smaller and the injection-recovery well
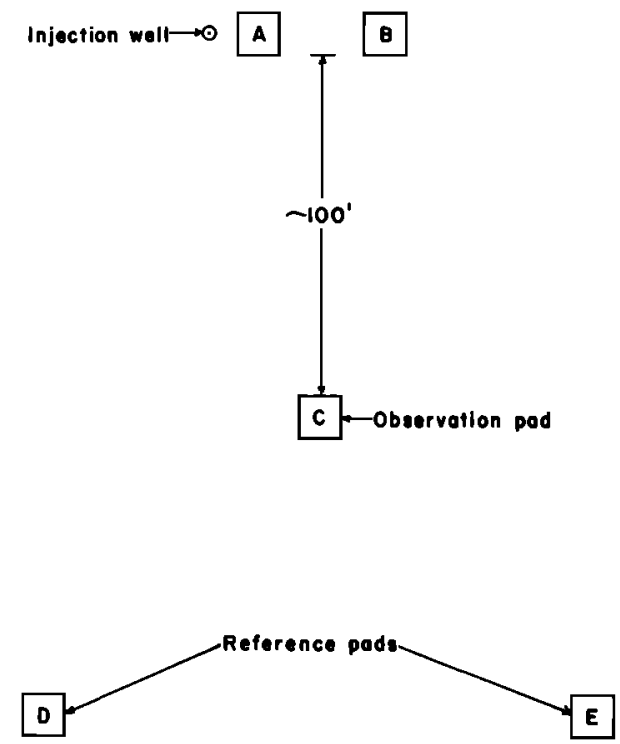

Fig. 5. Diagram showing the relative locations of the concrete pads used to monitor land surface elevation changes. 


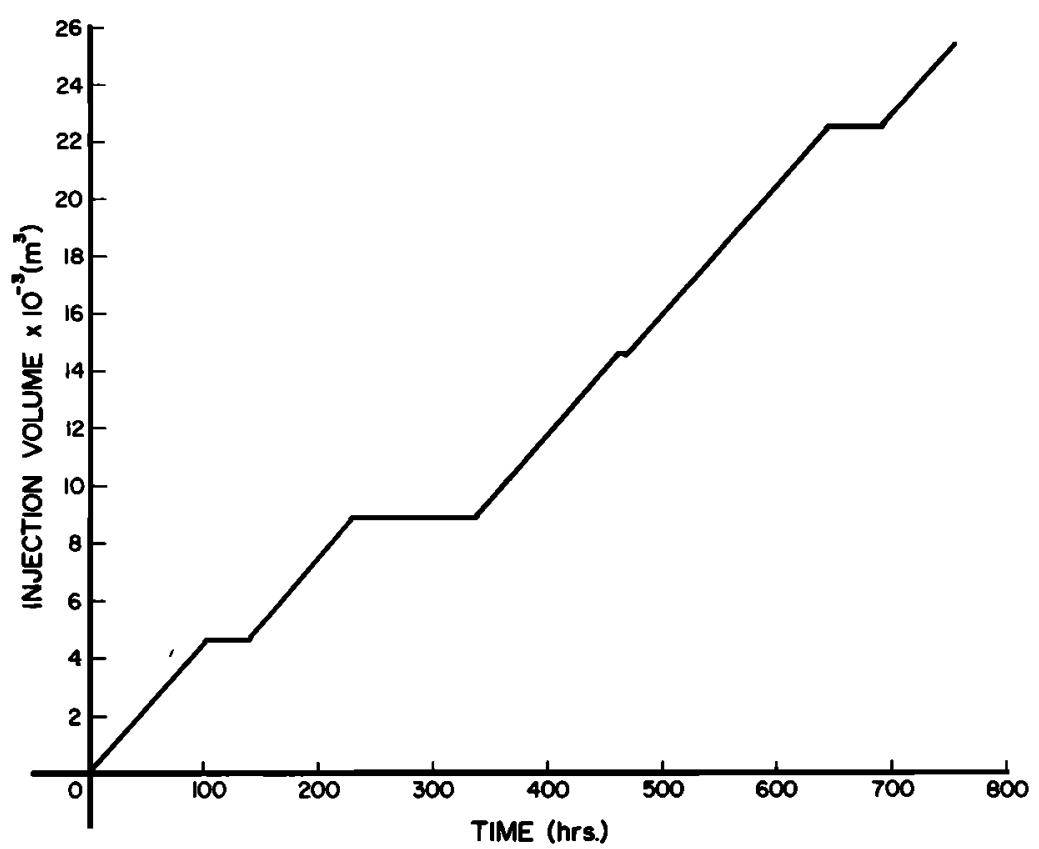

Fig. 6. Cumulative injection volume versus time for cycle $I$. The larger horizontal segments were time periods required for unexpected boiler maintenance.

was fully penetrating. Calculations indicate that $56 \%$ of the injected thermal energy was recovered in a volume of water equal to the injection volume.

Interpolated temperature contours in the aquifer along two vertical profiles at the beginning and end of storage are shown in Figures 13 and 14. At the end of the injection period there was a significantly greater radial displacement near the middle of the confined aquifer than near the upper and lower aquitards. Since the injection well, I2, was fully penetrating, it was concluded that the aquifer has variable horizontal hydraulic conductivity. In the direction of observation wells 10,11 , and 12 , the temperature distribution is more uniform vertically. It should also be noted that the thermal radius is not as large in this direction. This asymmetry is probably caused by a variable transmissivity. The regional flow velocity is a relatively small $0.8 \mathrm{~m} \mathrm{month}^{-1}$ in a northeasterly direction.

Because of the relatively low initial recovery temperature, it was suspected that a significant amount of free thermal convection occurred during the storage period. Although significant convection was not observed in previous experiments, we were

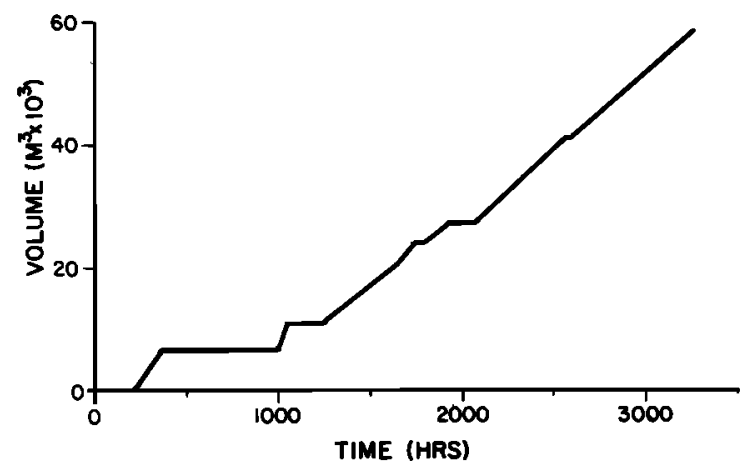

Fig. 7. Cumulative injection volume versus time for cycle II. During the first 1000 hours of the cycle, boiler malfunction continued to be a problem. now in a portion of the aquifer with slightly higher horizontal permeability and perhaps a significantly higher vertical permeability [Papadopulos and Larson, 1978]. Also, we were working with higher injection temperatures with correspondingly greater buoyant forces to induce convection.

Shown in Figure 15 is a plot of groundwater temperature versus time at six locations in observation well 4 which is approximately $15-\mathrm{m}$ east of the injection well. The thermal front arrived at the central thermistors 100 hours after the start of injection. About $\mathbf{8 0}$ hours later it arrived at the thermistors above and below the central thermistors, which is indicative of a significantly higher flow velocity near the center of the aquifer which, as mentioned previously, is reflected in Figures 13 and 14. This pattern was repeated in well 1 . In wells 7 and 10 the high permeability zone appeared to be a little below the center of the aquifer and less well defined in well 10.

The temperature variation recorded in well 4 shown in Figure 15 indicates that the bottom thermistor must be located in a very low permeability zone, which is probably an upward

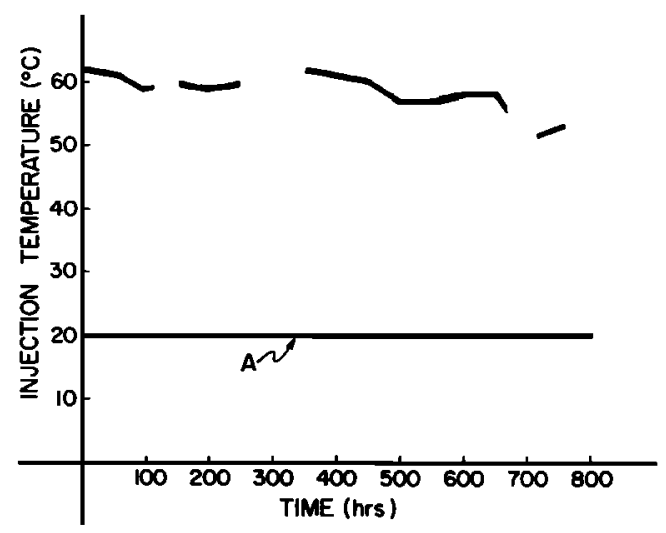

Fig. 8. Injection temperature versus time for cycle $I$. The line marked ' $A$ ' indicates the ambient groundwater temperature. 


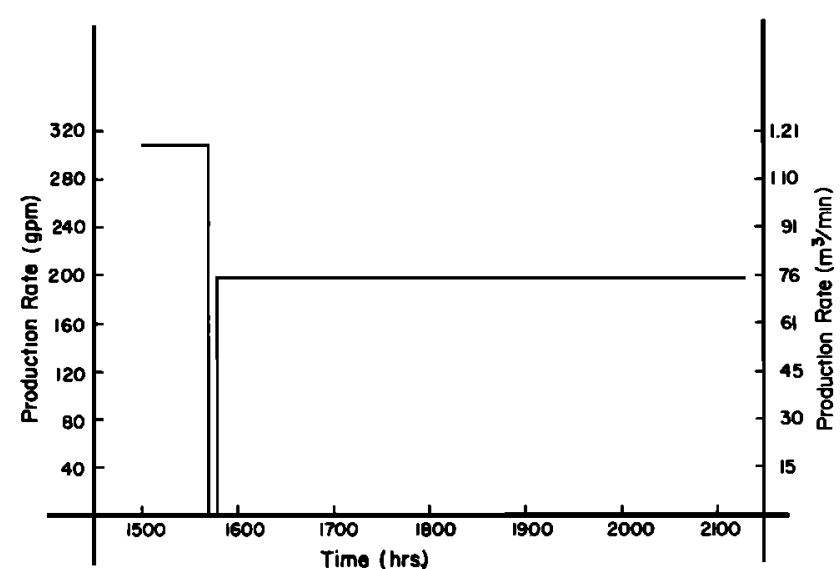

Fig. 9. Cycle I recovery pumping rate as a function of time.

extension of the lower aquitard. Heat is being conducted rather than advected to this position. There is no sharp thermal front, and the temperature continues to rise during the storage and part of the production periods. This is to be contrasted with the distinct temperature drop exhibited by thermistors 4 and 5 during the storage period. These thermistors are third and second from the bottom respectively, and the drop in temperature undoubtedly is due to the occurrence of free thermal convection. Such temperature decreases during storage occurred in one or more thermistors located in the lower zone of the aquifer at all four $15-\mathrm{m}$ temperature observation wells.

Evidence of a more integrated nature which indicates the occurrence of a significant amount of free thermal convection was obtained from the tracer experiment which was performed during cycle I [Parr et al., 1983]. Displayed in Figure 16 is a plot of tracer concentration versus time which was obtained for the injection-production well. The injection concentration averaged $12.5 \mathrm{mg} \mathrm{l}^{-1}$ during the first 400 hours of injection and $18.8 \mathrm{mg} 1^{-1}$ during the remaining 350 hours of injection. No samples were taken from $I 2$ during the storage time.

Samples taken at recovery initiation show an immediate drop to approximately $15 \mathrm{mg} \mathrm{l}^{-1}$ from the last injection concentration of $18.8 \mathrm{mg} \mathrm{l}^{-1}$. Vertical convection induced by buoyant forces during storage could cause the intrusion of native water at the bottom of the pumping well, which would dilute the recovered water and lead to the sudden decline of tracer concentration which was observed. The predicted recovery concentration based on a simple radial flow model without convection is shown also in Figure 16. Comparison of the two curves is consistent with the occurrence of significant thermal convection. The estimated local dispersivity of $0.3-3 \mathrm{~m}$ is not nearly large enough to account for the low initial production concentration [Parr et al., 1983].

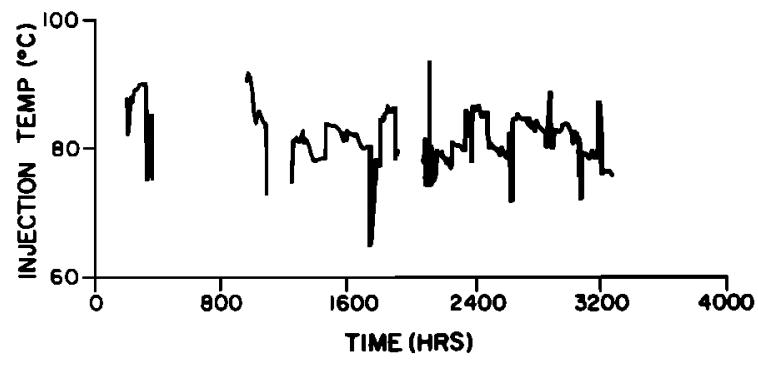

Fig. 10. Cycle II injection temperature as a function of time.

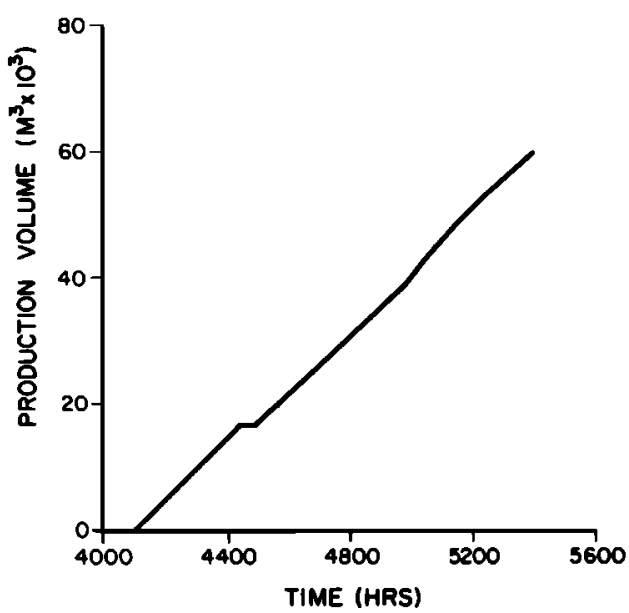

Fig. 11. Cumulative production volume versus time for cycle II.

A notable result during the first cycle was the absence of injection well clogging due to clay particle swelling, dispersion, and migration. During previous experiments, this phenomenon was identified as the major technical problem [Molz et al., 1979, 1981]. As was mentioned in the introduction, osmotic swelling occurs when clay platelets in equilibrium with groundwater having a relatively high ion concentration come in contact with water having a relatively low ion concentration. Such a situation occurred in previous experiments at the Mobile site when relatively pure supply water from a shallow aquifer was heated and injected into a deeper storage aquifer. In the present experiments, supply water was obtained directly from the storage aquifier, and $\mathrm{NaBr}$ was added which increased the $\mathrm{Na}$ concentration by about $5 \mathrm{mg} \mathrm{l}^{-1}$. Thus the water injected had a slightly higher cation concentraion than the native groundwater, which would further retard osmotic swelling.

Shown in Figure 17 is the best specific capacity history obtained in previous experiments [Molz et al., 1981] along with that obtained in the present cycle I. In the previous experiment, regular backwashing was required in order to maintain an acceptable injection rate. Backwashing was initiated whenever the injection pressure reached $0.145 \mathrm{MPa}(21 \mathrm{psi})$. This is to be contrasted with the present cycle I, where the injection pressure remained stable over relatively long periods of time and the specific capacity was 5 to 15 times larger than that obtained previously.

Lack of clay particle dispersion was indicated also by the relatively low suspended solids concentration in the water reco-

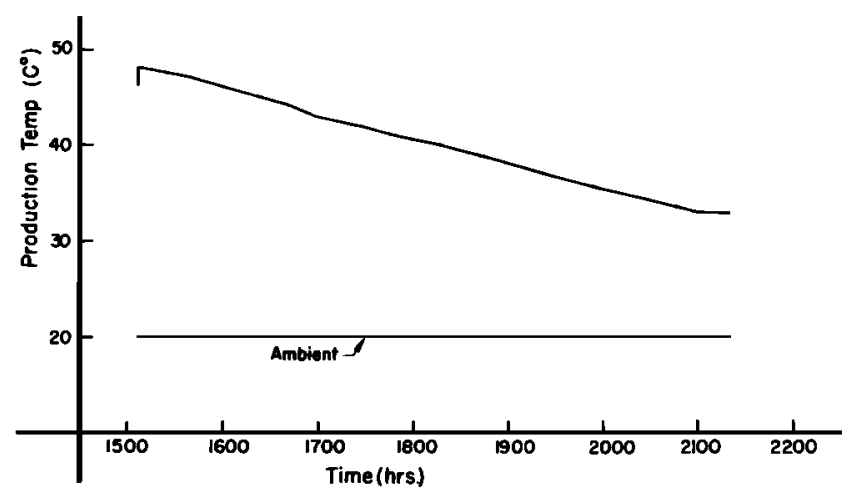

Fig. 12. Production temperature versus time for cycle $\mathrm{I}$. 

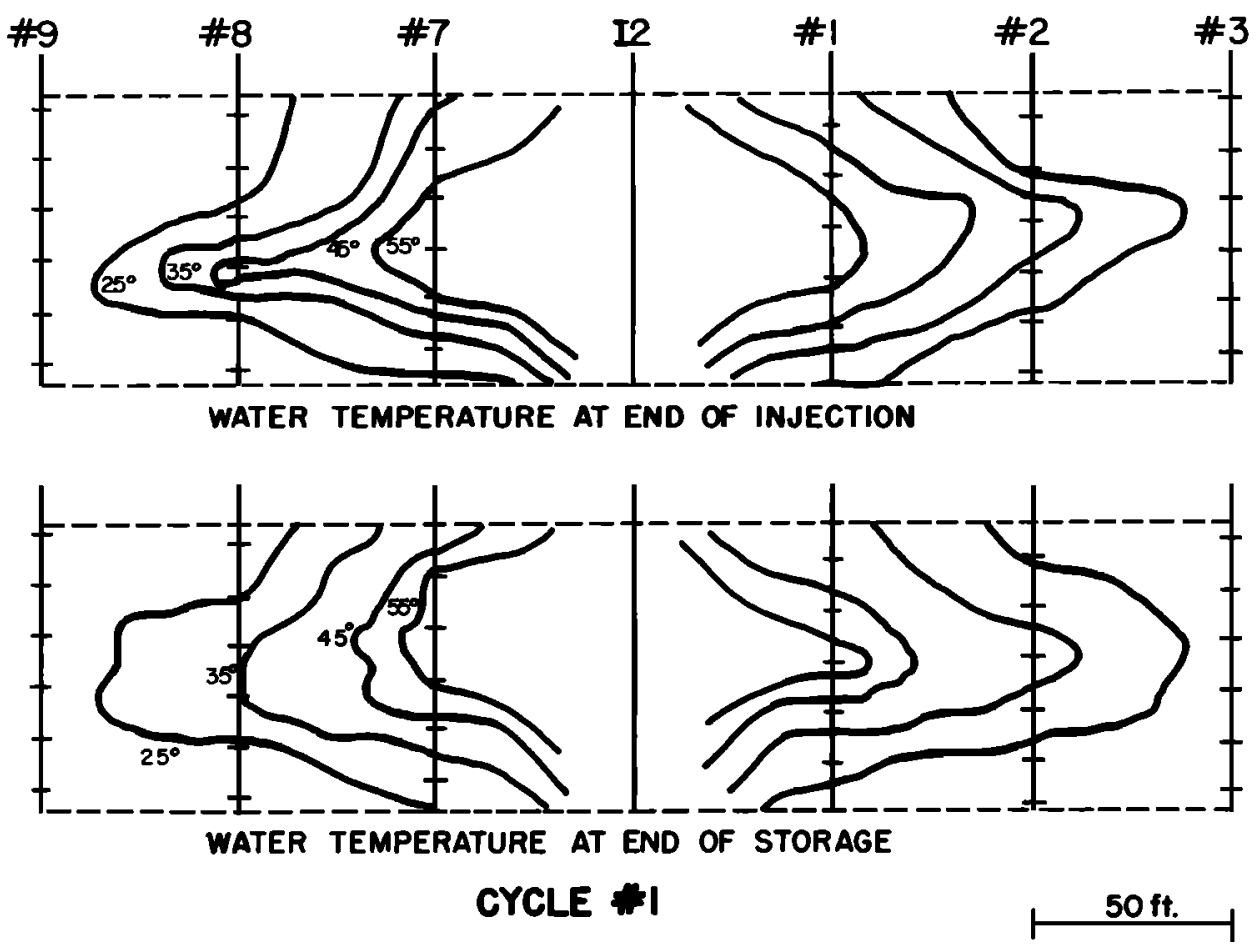

Fig. 13. Interpolated groundwater temperature profiles at selected times during cycle $\mathbf{I}$. The vertical sections run between wells 9 and 3 (Figure 2).

vered from the storage zone and reinjected to the supply zone. During cycle I the average value was $2.7 \mathrm{mg}^{-1}$. In previous comparable experiments, suspended solids averaged $35 \mathrm{mg}^{-1}$ [Molz et al., 1981].
Results of SeCond Cycle

On the basis of the results of cycle I, there was concern that free thermal convection would be an even more severe problem

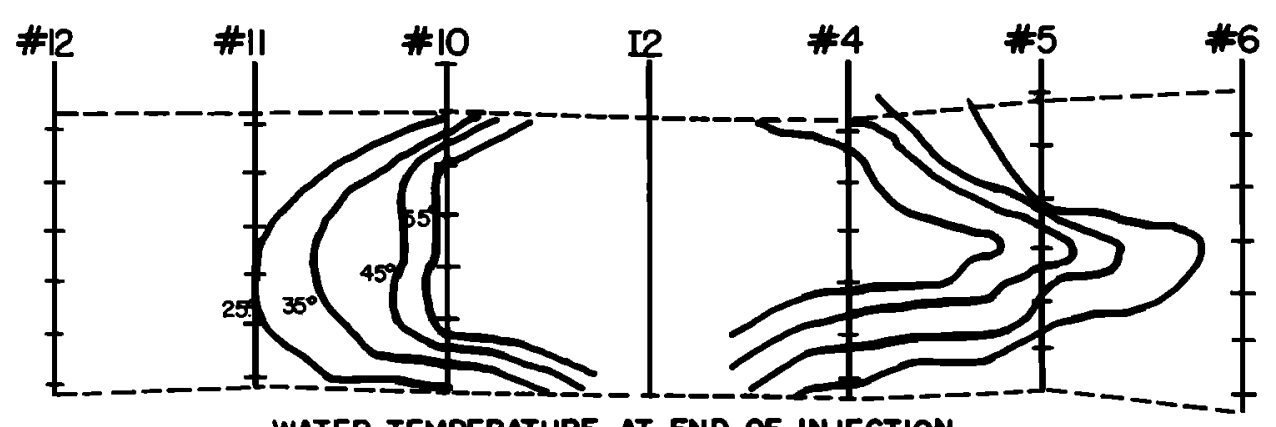

WATER TEMPERATURE AT END OF INUECTION

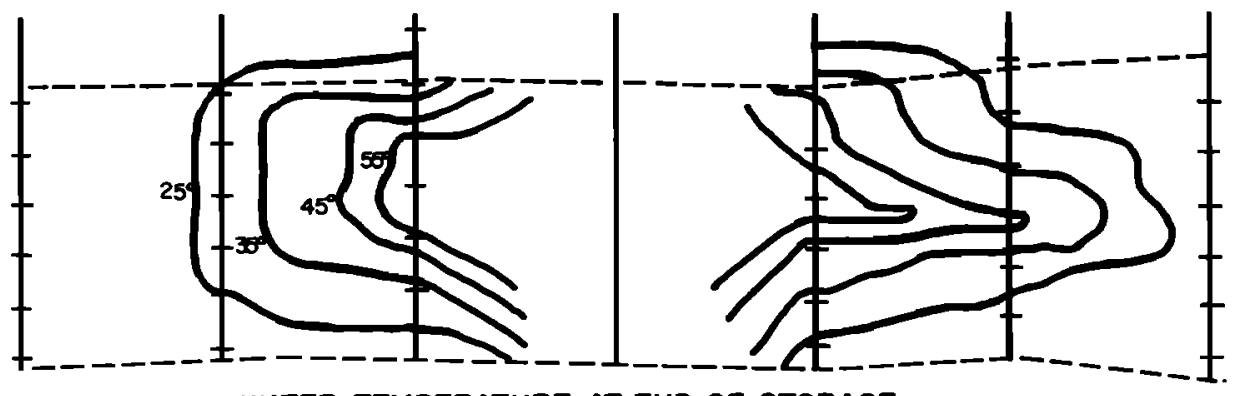

WATER TEMPERATURE AT END OF STORAGE

CYCLE \#I

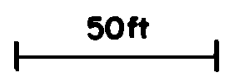

Fig. 14. Interpolated groundwater temperature profiles at selected times during cycle I. The vertical sections run between wells 12 and 6. 


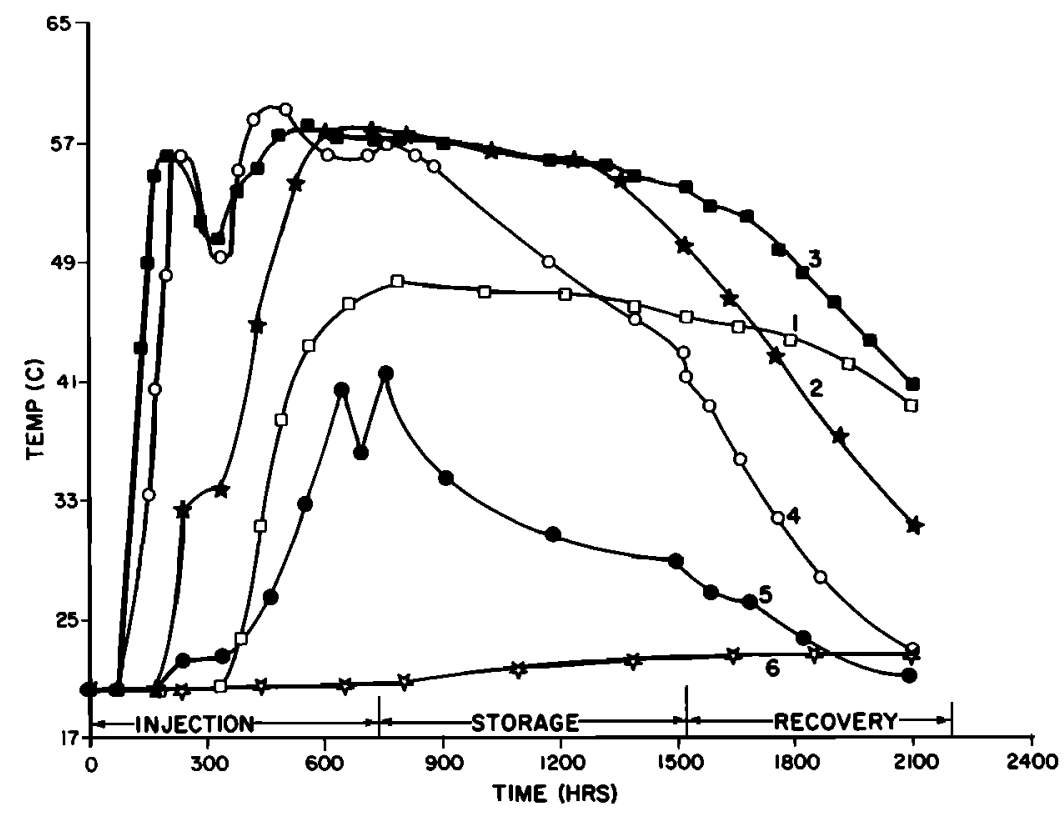

Fig. 15. Groundwater temperature as a function of time for well 4 during cycle 1 . The numbers next to the curves correspond to the thermistor locations shown in Figure 3.

at the higher injection temperature planned for cycle II, which averaged $81^{\circ} \mathrm{C}$. As is shown in Figure 18, the concern was well founded. Shortly after production pumping was initiated, the recovery temperature peaked at $55.1^{\circ} \mathrm{C}$ and began to decline. Within 2 weeks the recovery temperature dropped into the upper forties, and an energy recovery of less than $45 \%$ was projected in a recovery volume equal to the injection volume.

Examination of groundwater temperature data clearly indicated significant free thermal convection. Shown in Figure 19 are average temperature contours on a radial section of the storage aquifer at three different times. Of particular interest are the positions of the $25^{\circ} \mathrm{C}$ and $35^{\circ} \mathrm{C}$ isotherms at the end of injection and 2 weeks after the beginning of recovery, shown in
Figure $19 a$ and $19 b$ respectively. An upward migration of heat during and after the storage period was apparent. Because of the segregation of hot and cold water, a relatively large fraction of the injected heat remained in the aquifer after recovery was terminated.

In an attempt to improve energy recovery, production pumping was halted on December 14, 1981, so that the recovery well (I2) could be modified. The bottom half of the well was filled with sand, and a figure $k$ packer was placed above the sand. It was reasoned that pumping only from the upper half of the production well would pull relatively more water from the upper and hotter portion of the storage aquifer. On December 16 , recovery was resumed.

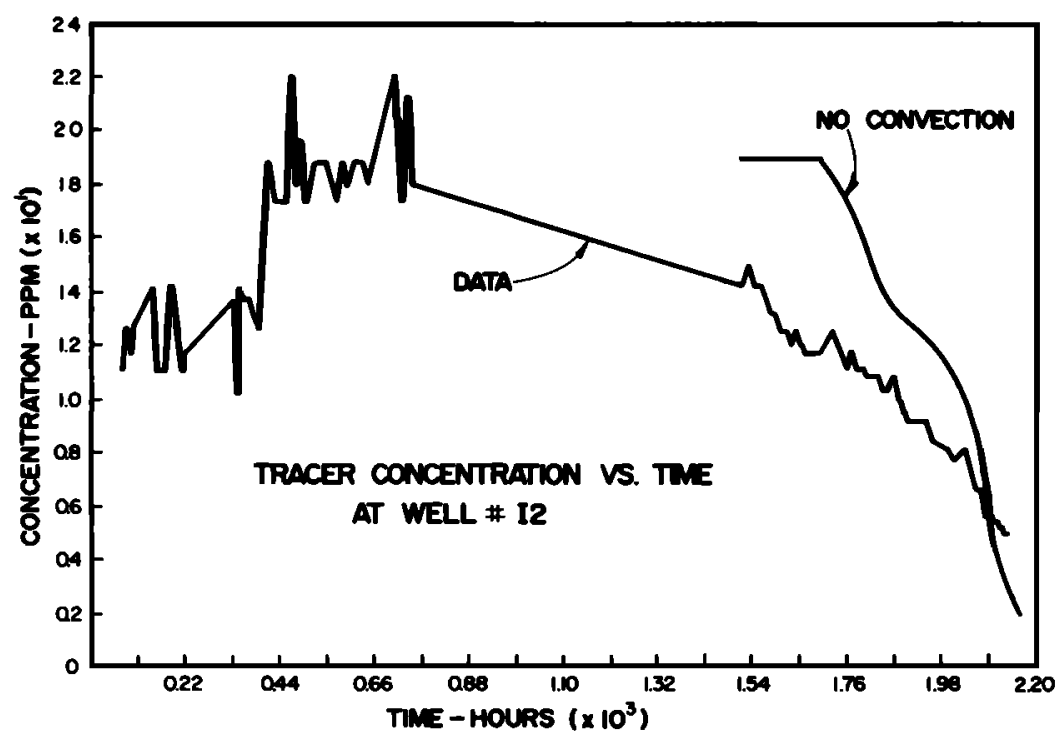

Fig. 16. Tracer concentration versus time at the injection-production well. The curve labeled 'No convection' is a theoretical prediction of the concentrations that should have resulted in the absence of free thermal convection. 


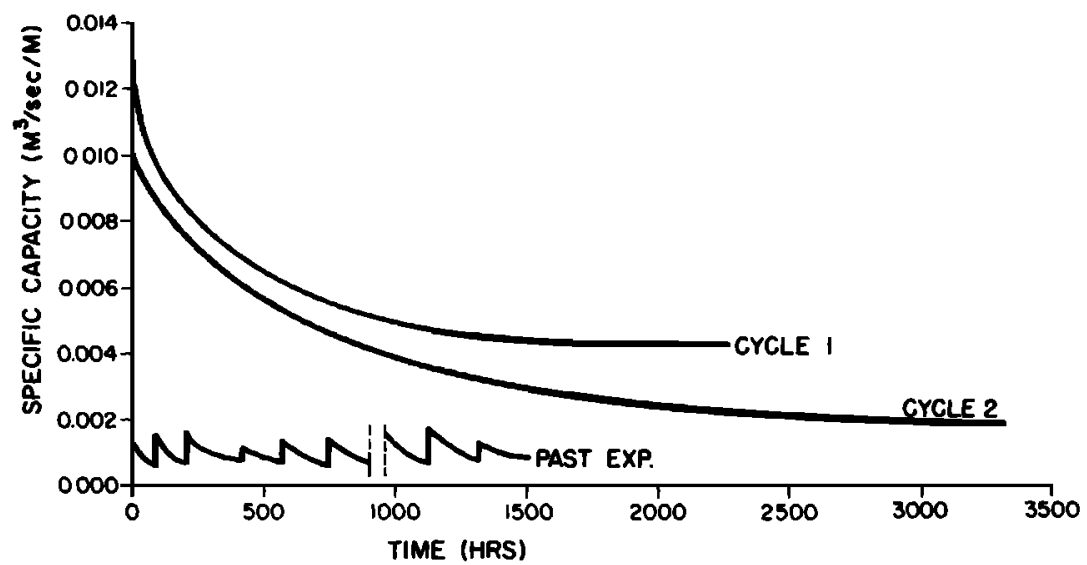

Fig. 17. Specific capacity of the injection-production well during cycle I, cycle II, and a previous experiment when clogging occurred because of clay dispersion.

The result of recovery well modification can be seen clearly in Figure 18. Upon resumption of pumping, the recovery temperature jumped from $49.5^{\circ} \mathrm{C}$ to $52.5^{\circ} \mathrm{C}$, which is reflected by the discontinuity in the temperature versus time curve at $\mathbf{4 4 3 0}$ hours. Ultimately, the energy recovered in a volume of water equal to the injection volume was $45.2 \%$. On the basis of linear extrapolations of the two temperature curve segments, it was estimated that the energy recovery would have been $40 \%$ if modifications had not been made and $46-47 \%$ if modifications had been made prior to initiation of the production period. Thus an energy recovery increase of approximately $16 \%$ would have been obtainable with the type of modifications that were

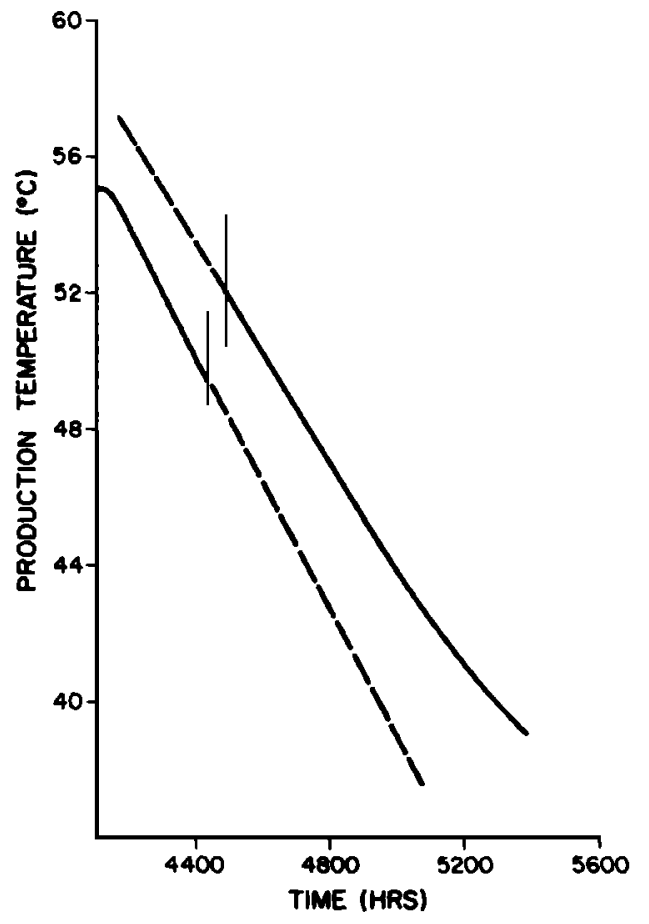

Fig. 18. Production temperature versus time for cycle II. The solid lines represent actual data obtained before and after the recovery well modifications discussed in the text. The broken lines are linear extrapolations of the two segments of data. made. It would have been possible to recover additional energy if the effective penetration of the recovery well had been reduced significantly below $50 \%$. Computer simulations, using a model validated with previous data from the Mobile site [Tsang et al., 1981], have been run to estimate the influence of partial penetration on recovery efficiency. In all cases, however, recovery factors of less than $51 \%$ were projected (LawrenceBerkeley Laboratory, personal communication, 1982). Therefore it must be concluded that partially penetrating recovery wells alone are to a significant extent incapable of overcoming the negative effects of free thermal convection in ATES.

Cycle II was similar to cycle I in that no clogging of the injection well was observed during injection. The specific capacity history is shown in Figure 17. During production the average suspended solids concentration was $1.8 \mathrm{mgl}^{-1}$.

At the higher injection temperature utilized in cycle II, rela-
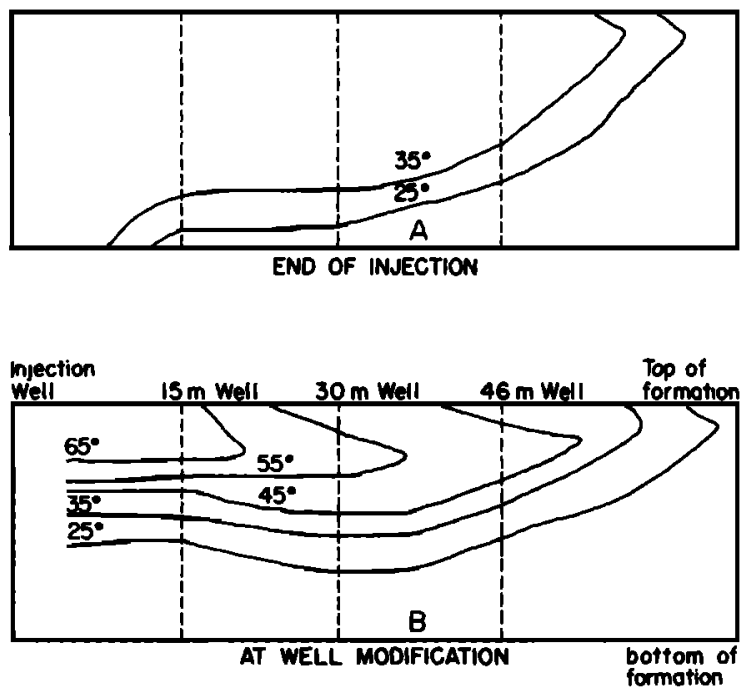

Fig. 19. Average radial temperature profiles in a vertical section at selected times during cycle II. To obtain the plots, data from observation wells at equal radial distances from the injection-production well were averaged. The shapes of the curves outside the zones where data were collected were inferred from computer simulations (LawrenceBerkeley Laboratory, personal communication, 1982). 


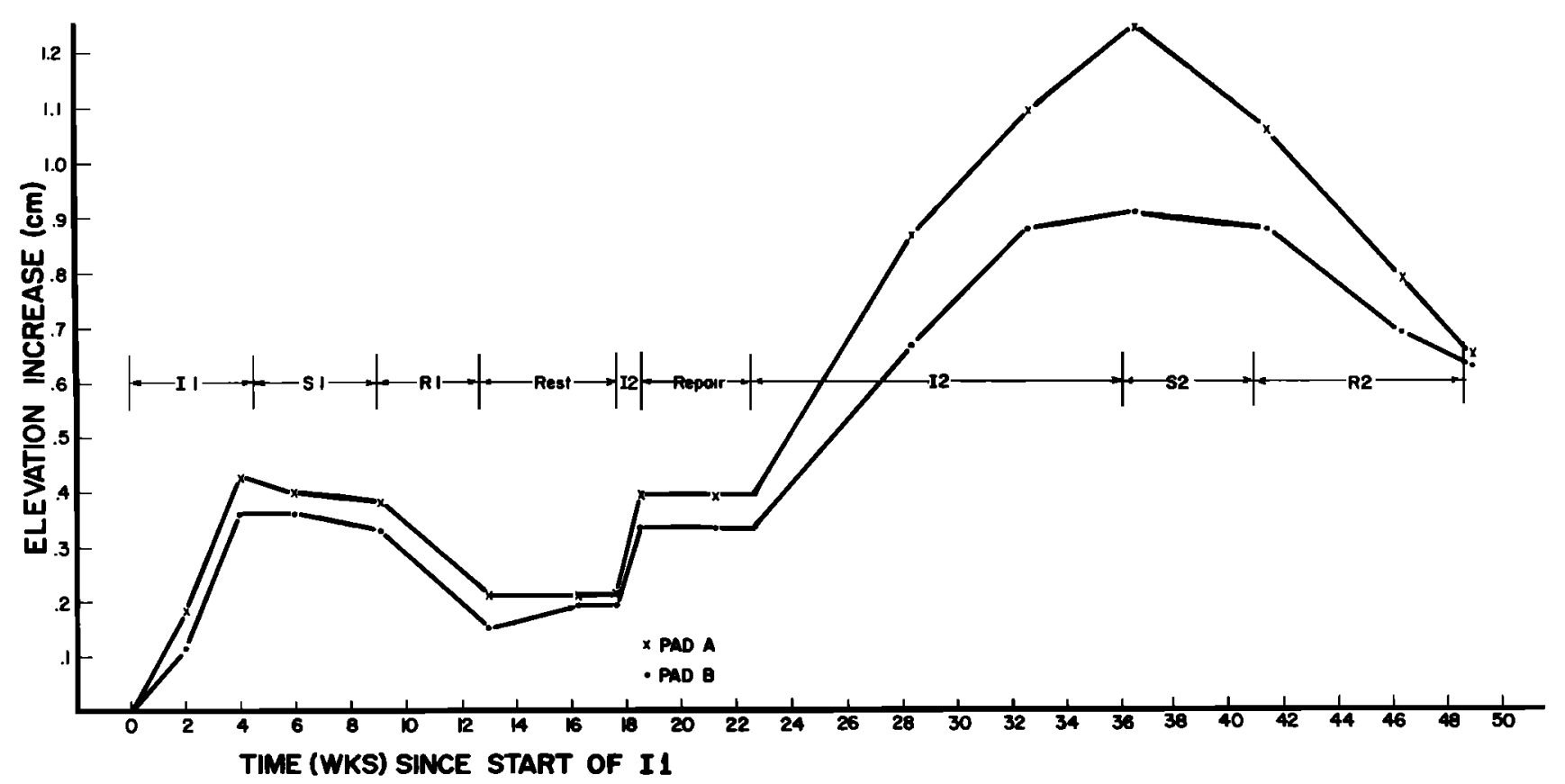

Fig. 20. Land surface elevation as a function of time during cycles I and II. Pads A and B are located near the injection-production well as indicated in Figure 5.

tively large volumes of gas (mostly $\mathrm{CO}_{2}$ ) were driven out of solution, and it was necessary to devise a mechanism for gas release. This was accomplished readily through the use of an open standpipe near the injection well. The $5-\mathrm{cm}$ diameter pipe was about $3.5 \mathrm{~m}$ tall, so that the injection pressure did not cause overflow but gas could bubble out freely.

Throughout the first and second cycles, relative land elevation changes were recorded between two points near the injection-production well (I2) and two benchmarks located beyond the thermal radius of influence (Figure 5). The results of these measurements are shown in Figure 20. By the end of first cycle injection, the land surface $4.6 \mathrm{~m}$ from the injection well had risen $0.43 \mathrm{~cm}$. The maximum elevation increase of $1.24 \mathrm{~cm}$ was recorded near the end of cycle II injection. This magnitude of surface elevation change is not negligible and would have to be considered, especially if an ATES system were being designed in an urban environment. Depending on local stratigraphy, injection temperature, and injection volume, elevation changes of 2 or $3 \mathrm{~cm}$ or more would seem possible.

In a previous publication, it was concluded that surface elevation changes observed at the Mobile ATES test site were due to thermal expansion of low-permeability, water-saturated clays [Molz et al., 1981]. Heat causing such expansion could flow upward and downward from the storage aquifer as well as radially outward from the well bore. Pressure effects due to injection appeared to cause negligible surface elevation changes. The present results lend further support to this viewpoint. Injection pressures were at least 5 times less than in previous experiments, but land elevation changes were greater by a factor of 3 due mainly to increased injection temperatures.

As mentioned previously, tracer experiments were performed during both injection-storage-recovery cycles, and dispersivity estimates were made as described in some detail by Parr et al. [1983]. Breakthrough curves obtained in an observation well $15 \mathrm{~m}$ from the injection well and screened in the middle $1.5 \mathrm{~m}$ of the storage aquifer (well 15) resulted in an apparent local dispersivity average of $6.3 \mathrm{~cm}$, which is among the lowest values ever measured in the field [Gelhar and Axness, 1981]. Analysis of cycle I recovery data at well 15 indicated a larger apparent dispersivity that was definitely less than $3 \mathrm{~m}$ and probably less than $1 \mathrm{~m}$. The precise interpretation of these latter data was made difficult by the fact that free thermal convection occurred during the storage and recovery portions of the experiment. Field results similar to ours were obtained previously in a sandy aquifer by Pickens et al., [1977].

During second cycle injection it became increasingly evident that many of the thermistors located in the hotter zones of the storage aquifer were becoming defective. Two thermistor strings were recovered, and detailed laboratory examination of several failed thermistors confirmed that the problem resided in the body of the thermistor itself. No mechanical damage could be detected, so it was concluded tentatively that the problem was chemical in nature, probably due to unexpectedly rapid water migration through the epoxy barrier used to isolate the thermistor from the surrounding groundwater. Evidently, such migration is accelerated significantly by temperatures above $60^{\circ} \mathrm{C}$.

The thermistor manufacturers agreed with our tentative conclusions and suggested that future thermistor temperature probes be sealed in neoprene. This was the most impervious, readily usable material that they had been able to locate. On December 21, 1981, five new strings of neoprene-sealed thermistor probes were installed at the Mobile site. To date (May $13,1982)$ they have been operating at temperatures up to the $85^{\circ} \mathrm{C}$ range with no evidence of malfunction. The new probes should be able to operate up to a maximum of $100^{\circ} \mathrm{C}$.

\section{Summary and Conclusions}

This paper deals with the first two injection-storage-recovery cycles of the third set of aquifer storage experiments to be conducted by Auburn University at the Mobile, Alabama, field test facility. A 3-month cycle followed by a 7.3-month cycle constituted the main experiment. The injection volumes were $25,402 \mathrm{~m}^{3}$ and $58,063 \mathrm{~m}^{3}$ at average temperatures of $58.5^{\circ} \mathrm{C}$ and 
$81^{\circ} \mathrm{C}$ respectively. During both cycles, $\mathrm{Br}$ tracer concentrations were monitored in several observation wells, and relative land surface elevation changes were recorded.

Cycle I production temperature was lower than expected, which resulted in a thermal energy recovery of $56 \%$ in a volume of water equal to the injection volume. There was distinct tracer and temperature profile evidence that free thermal convection in the storage aquifer contributed to the relatively low energy recovery. However, the measured groundwater temperature distributions also indicated the existence of high-permeability zones in the aquifer which could have contributed to unexpected mixing between the injected and native waters. With this situation, there is a possibility for synergistic effects between free thermal convection and nonhomogeneities.

At the higher injection temperature $\left(81^{\circ} \mathrm{C}\right)$ of cycle II, free thermal convection was more pronounced, and the initial recovery temperature was only $55.1^{\circ} \mathrm{C}$. By 2 weeks into the production period, water above $45^{\circ} \mathrm{C}$ had floated to the top half of the storage aquifer. At this time it was decided to modify the recovery well in an attempt to improve energy recovery. The bottom half of the well was filled with sand, and a figure $k$ packer was placed above the sand. After this modification was complete, pumping resumed, and ultimately, the energy recovered in a volume of water equal to the injection volume was $45.2 \%$. On the basis of linear extrapolations of the temperature curve segments before and after modification, it was estimated that the energy recovery would have been $40 \%$ if modifications had not been made and $46-47 \%$ if modifications had been made prior to initiation of the production period. Thus an additional $7 \%$ of the injected energy would have been obtainable with the type of modifications that were made. It would have been possible to recover additional energy if the effective penetration of the recovery well had been reduced significantly below $50 \%$. In all practical cases, however, recovery factors less than 0.51 are projected on the basis of computer simulations (Lawrence-Berkeley Laboratory, personal communication, 1982). Therefore it must be concluded that partially penetrating recovery wells alone are to a significant extent incapable of overcoming the negative effects of free thermal convection in ATES.

A positive result realized during both cycles was the absence of injection well clogging due to clay particle swelling, dispersion, and migration. In past experiments this phenomenon was a major technical problem [Molz et al., 1979, 1981]. Lack of the problem during the present set of experiments is attributed to the fact that the cation concentration in the supply water used for injection was equal to or slightly greater than that in the native groundwater.

By the end of first cycle injection, the land surface $4.6 \mathrm{~m}$ from the injection well had risen $0.43 \mathrm{~cm}$. The maximum elevation increase of $1.24 \mathrm{~cm}$ was recorded near the end of second cycle injection. Such a surface elevation change is not negligible, and its potential effect on foundations would have to be considered, especially if an aquifer thermal energy storage system were being designed in an urban environment. Depending on local stratigraphy, injection temperature (assumed $<100^{\circ} \mathrm{C}$ ), and injection volume, it is estimated that elevation changes of 2 or 3 $\mathrm{cm}$ or more are possible.

In previous studies it was concluded that the observed surface elevation changes were due to thermal expansion of lowpermeability, water-saturated clays and not due to expansion of the storage aquifer matrix or injection pressure. The present results further support this conclusion. Injection pressures were smaller than those in previous experiments by at least a factor of 5 , but land elevation changes were greater by a factor of 3 mainly because of the increased injection temperature.

The portions of our tracer studies dedicated to estimating longitudinal dispersivity were inconclusive. Data which would be expected to yield a relatively representative value for aquifer dispersivity were complicated by thermal convection effects. Early data collected $15 \mathrm{~m}$ from the injection well yielded an apparent local dispersivity average of $6.3 \mathrm{~cm}$, which is almost certainly not representative of the overall aquifer.

After consideration of the free thermal convection problem and its negative effect on recovery temperature it was concluded that a dual-recovery well system might result in improved energy recovery. The two wells would be located as close together as possible, with one well screened in the upper half of the storage aquifer and the other screened in the lower half. Upon initiation of recovery pumping, both wells would be pumped simultaneously. In a thermally stratified and homogeneous storage aquifer this would maintain radial flow approximately, with colder water entering the lower screen and warmer water entering the upper screen. The colder water could then be reinjected at an appropriate location. The effect of nonhomogeneities, which we know exist at the Mobile site, cannot be predicted in detail but would probably act to reduce the effectiveness of the dual-well system.

At the Mobile site, construction of a dual-recovery well system was completed on April 1, 1982. The two wells are separated horizontally by $1.8 \mathrm{~m}$, with the upper production well screened in the top $9.1 \mathrm{~m}$ of the storage aquifer. Presently, this well is being used for third cycle injection which was started on April 7, 1982. The screen for the lower production well is also $9.1 \mathrm{~m}$ in length. It begins $1.5 \mathrm{~m}$ below the bottom of the upper screen.

Tentatively, it is planned to begin third cycle storage during the first half of July. Production would then begin in September, which would allow testing of the dual-recovery well system.

Acknowledgments. This work was made possible through support of the U.S. Department of Energy and the Battelle Pacific Northwest Laboratories (subcontract B-67770-A-0). The Alabama Power Company allowed us to conduct the experiment on their land and also maintained the roads leading to the site. This help is gratefully acknowledged. In addition, the writers would like to thank Rod Jenkins, Lance Bell, and Larry Benefield, associate professors of civil engineering, Auburn University, for performing the land surface elevation and $\mathrm{Br}$ measurements reported in this paper. Many fruitful discussions with staff members of the Battelle Pacific Northwest Laboratory and the Lawrence-Berkeley Laboratory are acknowledged also. The project was administered by the Auburn University Water Resources Research Institute.

\section{REFERENCES}

Brown, D. L., and W. D. Silvey, Artificial recharge to a freshwatersensitive brackish-water sand aquifer, Norfolk, Virginia, U.S. Geol. Surv. Prof. Pap. 939, U.S. Government Printing Office, Washington, D. C., 1977.

Doughty, C., G. Hellstrom, C. F. Tsang, and J. Claesson, A dimensionless parameter approach to the thermal behavior of an aquifer thermal energy storage system, Water Resour. Res., 18, 571-587, 1982.

Gelhar, L. W., and C. L. Axness, Stochastic analysis of macrodispersion in three dimensionally heterogeneous aquifers, $R e p . H-8,140$ pp., Geophys. Res. Center, N. M. Inst. of Mining and Technol., Socorro, N. M., 1981.

Molz, F. J., J. C. Warman, and T. E. Jones, Aquifer storage of heated water, 1, A field experiment, Ground Water, 16, 234-241, 1978.

Molz, F. J., A. D. Parr, P. F. Anderson, V. D. Lucido, and J. C. 
Warman, Thermal energy storage in a confined aquifer: Experimental results, Water Resour. Res., 15, 1509-1514, 1979.

Molz, F. J., A. D. Parr, and P. F. Andersen, Thermal energy storage in a confined aquifer: Second cycle, Water Resour. Res., 17, 641-645, 1981.

Papadopulos, S. S., and S. P. Larson, Aquifer storage of heated water, 2, Numerical simulation of field results, Ground Water, 16, 242-248, 1978 .

Parr, A. D., F. J. Molz, and J. G. Melville, Aquifer testing for thermal energy storage, Ground Water, 21, in press, 1983.

Pickens, J. F., W. F. Merritt, and J. A. Cherry, Field determination of physical contaminant transport parameters in a sandy aquifer, paper presented at Advisory Group Meeting, Int. Atomic Energy Agency, Poland, 1977.
Tsang, C. F., T. Buscheck, and C. Doughty, Aquifer thermal energy storage: A numerical simulation of Auburn University field experiments, Water Resour. Res., 17, 647-658, 1981.

U.S. Department of Energy (USDOE), Proceedings of the International Conference on Seasonal Thermal Energy Storage and Compressed Air Energy Storage, CONF-811066, vols. 1 and 2, Natl. Tech. Inf. Serv., Springfield, Va., 1981.

van Olphen, H., An Introduction to Clay Colloid Chemistry, John Wiley, New York, 1963.

(Received May 24, 1982;

revised October 6, 1982;

accepted October 18,1982 .) 